\title{
Gingival fibromatosis-facial dysmorphism syndrome
}

INSERM

\section{Source}

INSERM. (1999). Orphanet: an online rare disease and orphan drug data base. Gingival fibromatosis-facial dysmorphism syndrome. ORPHA:2025

Ging ival fibromatosis - facial dysmorphism is a very rare syndrome characterized by the association of gingival fibromatosis and craniofacial dysmorphism. 